\title{
Palpable Masses Assessment Test
}

National Cancer Institute

\section{Source}

National Cancer Institute. Palpable Masses Assessment Test. NCI Thesaurus. Code

C119920.

A character or string that represents the long name of the palpable masses assessment. 